University of New Hampshire

University of New Hampshire Scholars' Repository

Physics Scholarship

Physics

$1-1-1992$

\title{
On the standing wave mode of giant pulsations
}

K. Takahashi

N. Sato

J. Warnecke

H. Luhr

Harlan E. Spence

Boston University, harlan.spence@unh.edu

See next page for additional authors

Follow this and additional works at: https://scholars.unh.edu/physics_facpub

Part of the Physics Commons

\section{Recommended Citation}

Takahashi, K., N. Sato, J. Warnecke, H. Lühr, H. E. Spence, and Y. Tonegawa (1992), On the standing wave mode of giant pulsations, J. Geophys. Res., 97(A7), 10717-10732, doi:10.1029/92JA00382.

This Article is brought to you for free and open access by the Physics at University of New Hampshire Scholars' Repository. It has been accepted for inclusion in Physics Scholarship by an authorized administrator of University of New Hampshire Scholars' Repository. For more information, please contact Scholarly.Communication@unh.edu. 


\section{Authors}

K. Takahashi, N. Sato, J. Warnecke, H. Luhr, Harlan E. Spence, and Y. Tonegawa 


\title{
On the Standing Wave Mode of Giant Pulsations
}

\author{
K. Takahashr, ${ }^{1}$ N. Sato, ${ }^{2}$ J. Warnecke, ${ }^{3}$ H. LUtr, ${ }^{3}$ H. E. Spence, ${ }^{4}$ and Y. Tonegawa ${ }^{5}$
}

\begin{abstract}
Both odd-mode and even-mode standing wave structures have been proposed for giant pulsations. Unless a conclusion is drawn on the field-aligned mode structure, litule progress can be made in understanding the excitation mechanism of giant pulsations. In order to determine the standing wave mode, we have made a systematic survey of magnetic field data from the AMPTE CCE spacecrafi and from ground stations located near the geomagnetic foot point of CCE. We selected time intervals when CCE was close to the magnetic equator and also magnetically close to Syowa and stations in Iceland, and when either transverse or compressional Pc 4 waves were observed at CCE. Magnetograms from the ground stations were then examined to determine if there was a giant pulsation in a given time interval. One giant pulsation was associated with a compressional wave, while no giant pulsation was observed in association with transverse wave events. The CCE magnetic field record for the giant pulsation exhibited a remarkable similarity to a giant pulsation observed from the ATS 6 geostationary satellite near the magnetic equator (Hillebrand et al., 1982). In agreement with Hillebrand et al., we conclude that the compressional nature of the giant pulsation is due to an odd-mode standing wave structure. This conclusion places a strong constraint on the generation mechanism of giant pulsations. In particular, if giant pulsations are excited through the drift bounce resonance of ions with standing Alfvén waves, $\omega-m \omega_{d}= \pm N \omega_{b}$, where $\omega$ is the wave frequency, $m$ is the azimuthal wave number, $\omega_{d}$ is the ion drift frequency, $N$ is an integer, and $\omega_{b}$ is the ion bounce frequency, then the resonance must occur at an even $N$.
\end{abstract}

\section{INTRODUCTION}

Giant pulsations are a class of magnetic pulsations observed on the ground in the Pc 4 band (period = 45-150 s). The pulsations are most often observed in the morning sector at the auroral and lower latitudes and have a typical period of $100 \mathrm{~s}$ and a typical amplitude of the order of $10 \mathrm{nT}$. The most outstanding distinguishing feature of the pulsations is their sinusoidal waveform, which was recognized early in this century [Birkeland, 1901] and has continued to attract researchers since [Annexstad and Wilson, 1968; Green, 1979, 1985; Rostoker et al., 1979; Glassmeier, 1980; Kokubun, 1980; Kokubun et al., 1989; Chisham et al., 1990; Chisham and Orr, 1991]. Another important distinguishing feature is their polarization. In contrast to other types of Pc 4 pulsations, which are more frequently observed, the magnetic field perturbation of giant pulsations is larger in the east-west component than in the north-south component. Furthermore, multistation [Rostoker et al., 1979; Glassmeier, 1980; Hillebrand et al., 1982; Chisham et al., 1990] and radar [Poulter et al., 1983] observations established that giant pulsations propagate westward with an azimuthal wave number, $m$ (where the phase variation of pulsation signals with longitude, $\phi$, is expressed as $e^{i m \phi}$ ), of $16-35$; they are localized $\left(\sim 5^{\circ}\right)$ in latitude; and the sense of rotation of their magnetic perturbations changes from counterclockwise at low latitude to clockwise at high latitude.

\footnotetext{
${ }^{1}$ Applied Physics Laboratory, The Johns Hopkins Universily, Laurel, Maryland.

2National Institute of Polar Research, Tokyo.

${ }^{3}$ Institut für Geophysik und Meteorologie, Technische Universitât Braunschweig, Braunschweig, Germany.

4Space and Environment Technology Center, The Aerospace Corporation, El Segundo, Califomia

${ }^{5}$ Department of Aeronautics and Astronautics, Tokai University. Hiratsuka, Japan.
}

\section{Copyright 1992 by the American Geophysical Union.}

Paper number $92 \mathrm{JA00382.}$

0148-0227/92/92JA-00382\$05.00
From the azimuthal wave number, latitudinal localization, and occasional occurrences at $L<6$, we can conclude that giant pulsations are excited within the magnetosphere by a plasma instability. Penetration of external pressure perturbations to the $L$ shell of 5-6, or even to 3 [Green, 1985], and coupling with local field line oscillations is highly unlikely with $|\mathrm{m}|-20$ [Lee and Lysak, 1990]. To the authors' knowledge, no unique instability theory has been developed for giant pulsations, but instability theories proposed for specific types of geomagnetic pulsations observed in space have often been suggested as being applicable to giant pulsations. One such mechanism is the drift wave instability of compressional Alfvén waves [Hasegawa, 1971] applied to giant pulsations by Green [1979]. Another mechanism is drift bounce resonance of ring current ions with standing Alfvén waves [Southwood, 1973, 1976] applied to giant pulsations by Glassmeier [1980], Poulter et al. [1983], Chisham et al. [1990], Glassmeier et al. [1990], and Chisham and Orr [1991]. Neither of these mechanisms, however, has been tested using in situ particle measurements.

Although it is generally believed that giant pulsations are a standing wave on geomagnetic field lines, the harmonic mode (or the symmetry) of the standing wave has not been determined conclusively. This is one reason why the generation mechanism of the pulsations has not been determined. For example, the drift bounce resonance mechanism previously invoked requires the standing wave to be an even mode [Glassmeier, 1980; Poulter et al., 1983; Glassmeier et al., 1990; Chisham et al., 1990; Chisham and Orr, 1991]. Note that for field lines fixed at the ionosphere we define odd(even-) mode waves as those having an antinode (node) of field line displacement at the equator. Also note that odd (even) modes are often referred to as symmetric (antisymmetric) waves, based on their symmetry of field line displacement about the equator. The field line displacement for the first four harmonics is illustrated in Figure 1.

Previous studies used three different methods to infer the harmonic mode of giant pulsations. In the first method, ground magnetograms from north-south conjugate stations are compared and the phase lag of pulsation signals is determined. Using the string analogy of standing waves [Sugiura and Wilson, 1964], one can then infer whether the pulsation is an odd mode 


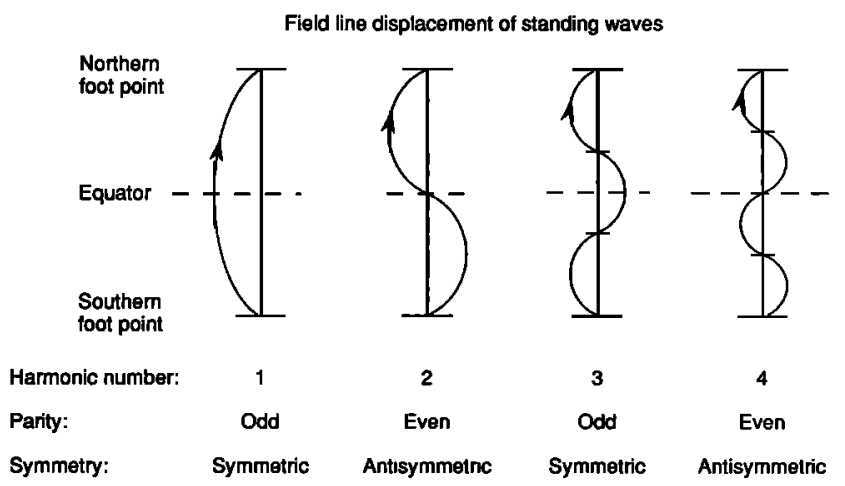

Fig. 1. Schematic illustration of the field line displacement of standing waves excited on geomagnetic field lines. For simplicity the dipole field lines are stretched straight with the end points fixed at the northem and southem ionosphere.

or an even mode. An early study using near-conjugate ground stations found an event showing the north-south phase lag of an even mode [Annexstad and Wilsom, 1968]. However, in another study, Green [1979] concluded that two events had an odd-mode standing wave structure. Tonegawa and Sato [1987] also concluded that a giant pulsation had an odd-mode structure.

In the second method the period of the observed pulsation is compared with the periods of standing waves calculated for a model magnetosphere. Using this method, Green [1985] concluded that giant pulsations observed within the plasmasphere had an odd-mode (fundamental) structure. By contrast, for giant pulsations generated at $L=6-8$, Chisham and Orr [1991] favor an even-mode (second harmonic) wave.

In the third method, spacecraft observations are used. Because the field line displacement is not a directly measurable quantity, one determines its symmetry from the associated magnetic field perturbation. In the inhomogeneous magnetosphere, compressional waves (fast mode) and transverse waves (Alfvén mode) are always coupled [e.g., Chen and Hasegawa, 1974; Southwood, 1974], so that the signatures of a standing wave appear in both the compressional and transverse magnetic field components. At the equator, for example, an odd-mode wave has a node of the transverse component and an antinode of the compressional component. The opposite occurs for an evenmode wave. Therefore, an equatorial satellite will observe an

TABLE 1. List of Ground Stations

\begin{tabular}{|c|c|c|c|c|c|}
\hline \multirow[t]{2}{*}{ Station } & \multirow[t]{2}{*}{ Code } & \multicolumn{2}{|c|}{ Geographic } & \multicolumn{2}{|c|}{ Geomagnetic } \\
\hline & & $\begin{array}{c}\text { Latitude, } \\
\text { deg }\end{array}$ & $\begin{array}{c}\text { Longitude, } \\
\text { deg }\end{array}$ & $\begin{array}{c}\text { Latitude, } \\
\text { deg }\end{array}$ & $\begin{array}{c}\text { Longitude, } \\
\text { deg }\end{array}$ \\
\hline \multicolumn{6}{|c|}{ Iceland/Antarctic Stations } \\
\hline Husafell & HUS & 64.67 & 338.97 & 65.71 & 69.99 \\
\hline Isafjordur & ISA & 66.08 & 336.87 & 67.59 & 69.49 \\
\hline Tjomes & TJO & 66.20 & 342.88 & 66.67 & 74.36 \\
\hline Syowa & SYO & -69.00 & 39.58 & -66.50 & 72.77 \\
\hline \multicolumn{6}{|c|}{ EISCAT Stations } \\
\hline Soroya & SOR & 70.54 & 22.22 & 67.13 & 107.71 \\
\hline Alta & ALT & 69.86 & 22.96 & 66.40 & 107.61 \\
\hline Munio & MUO & 68.01 & 23.53 & 64.50 & 106.45 \\
\hline Pello & PEL & 66.90 & 24.08 & 63.34 & 106.04 \\
\hline Kilpisjarvi & KIL & 69.05 & 20.70 & 65.71 & 105.16 \\
\hline Kevo & KEV & 69.76 & 27.01 & 66.10 & 110.60 \\
\hline
\end{tabular}

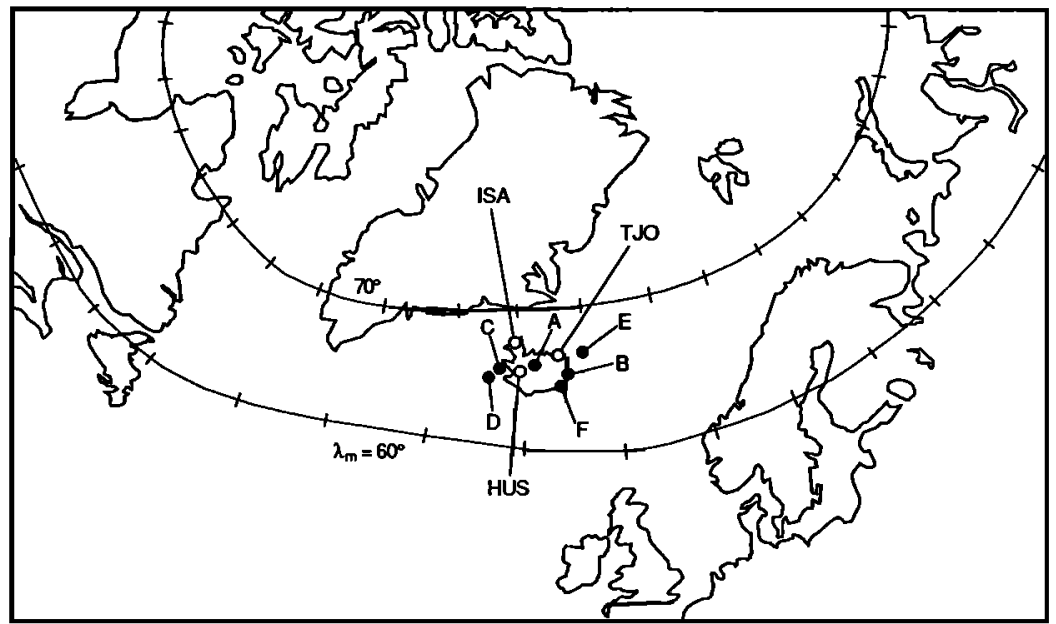

Fig. 2. Location of CCE foot points and the three ground stations in Iceland. The solid circles marked A through F are the CCE foot points for the time center of six transverse Pc 4 magnetic pulsations observed from CCE. The open circles indicate the three ground stations in Iceland. Two contours of constant magnetic latitude are drawn to indicate the separation between the foot points and the stations. The tick marks on the latitude contours indicate $10^{\circ}$ intervals in geomagnetic longitude. 
1984 August 25

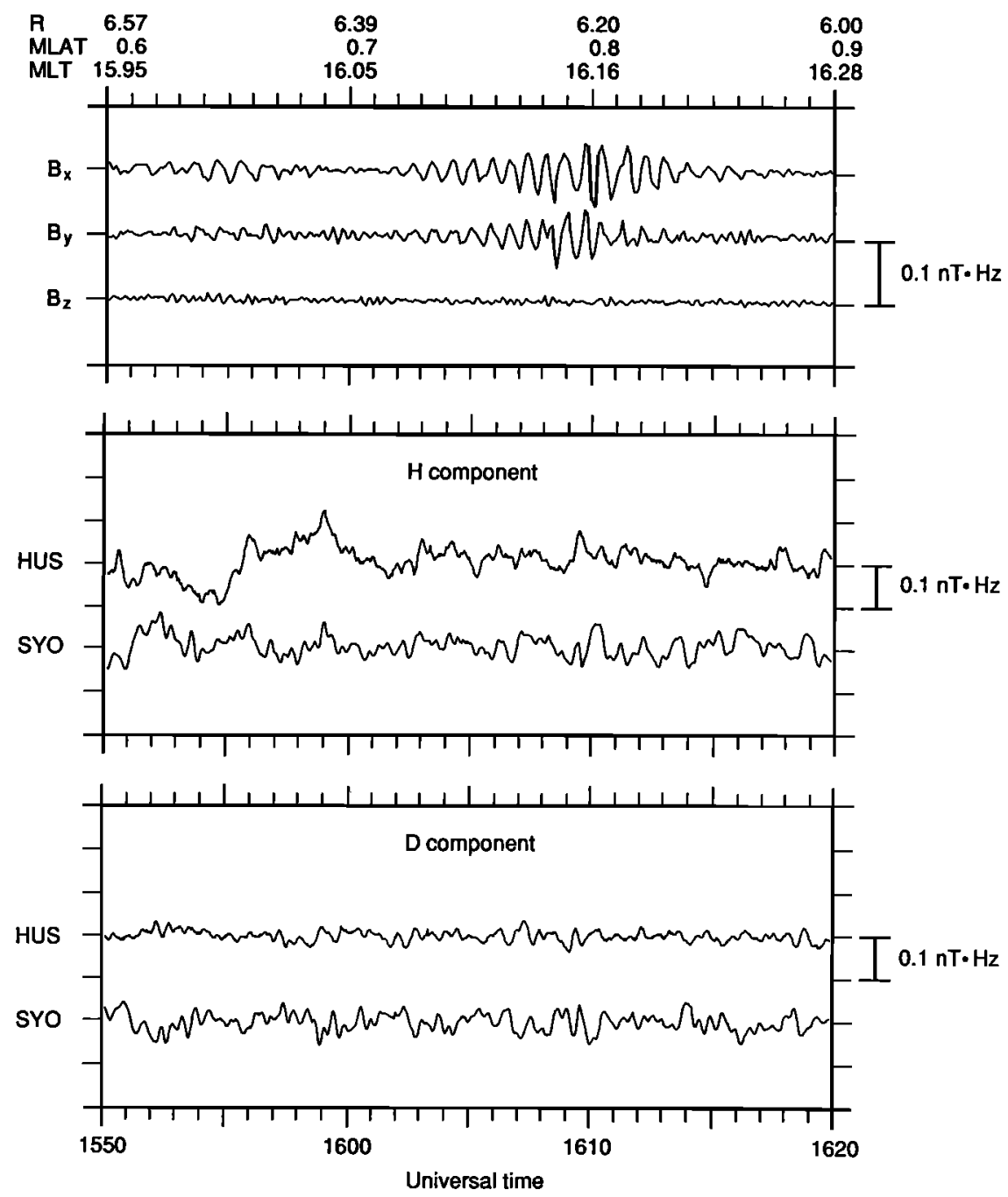

Fig. 3a. Magnetic field records from CCE and ground stations for the transverse Pc 4 event A. The location of CCE is indicated at the top using geocentric distance $R$ (Earth radii), dipole latitude MLAT (degrees), and dipole local time MLT (hours). Ground records are available from two stations.

odd-mode wave, as a purely compressional oscillation and an even-mode wave as a purely transverse oscillation. The only reported giant pulsation observed from a near-equatorial satellite (dipole latitude $=-5^{\circ}$ ) showed a strongly compressional oscillation and the very small transverse amplitude was taken as evidence for an odd-mode standing wave [Hillebrand $e t$ al., 1982]. An equatorial compressional Pc 4 wave observed by the ATS 1 geostationary satellite (magnetic latitude $\sim 2^{\circ}$ ) exhibited properties similar to those reported by Hillebrand et al. [1982], but whether the pulsation was a giant pulsation has not been discussed [Barfield et al., 1971; Lanzerotti and Tartaglia, 1972]. Kokubun et al. [1989] also favor an odd-mode wave, but their satellite observations, made $10^{\circ}$ away from the equator, give less conclusive information on the structure. Given these mixed results from ground and space observations, it is clear that more observations need to be made conceming the standing wave mode of giant pulsations.

In this paper we combine observations from the Active Magnetospheric Particle Tracer Explorers Charge Composition Explorer (AMPTE CCE) spacecraft and a number of ground stations to determine the standing wave mode of giant pulsa- tions. To determine the mode structure, we use the third approach described above: an odd-mode standing wave will be observed as a purely compressional magnetic pulsation if CCE is located near the magnetic equator, while an even-mode wave will be observed as a purely transverse pulsation. The low inclination of the CCE orbit and its nearly continuous operation for over 4 years allow us to select a number of candidate events occurring near the geomagnetic equator. Ground observations are used to find whether a giant pulsation occurred on the ground when $\mathrm{CCE}$ observed a pulsation. The ground data are important because we do not know, a priori, how giant pulsations would appear in the magnetosphere. From the examination of the ground and satellite data presented here we conclude that giant pulsations have an odd-mode standing wave structure.

The organization of the paper is as follows. In section 2 we describe the magnetic field experiments. In section 3 we examine the relation between transverse magnetic pulsations observed at CCE and magnetic pulsations observed on the ground. In section 4 we examine the relation between compressional magnetic pulsations observed at CCE and magnetic pul- 
1984 September 28

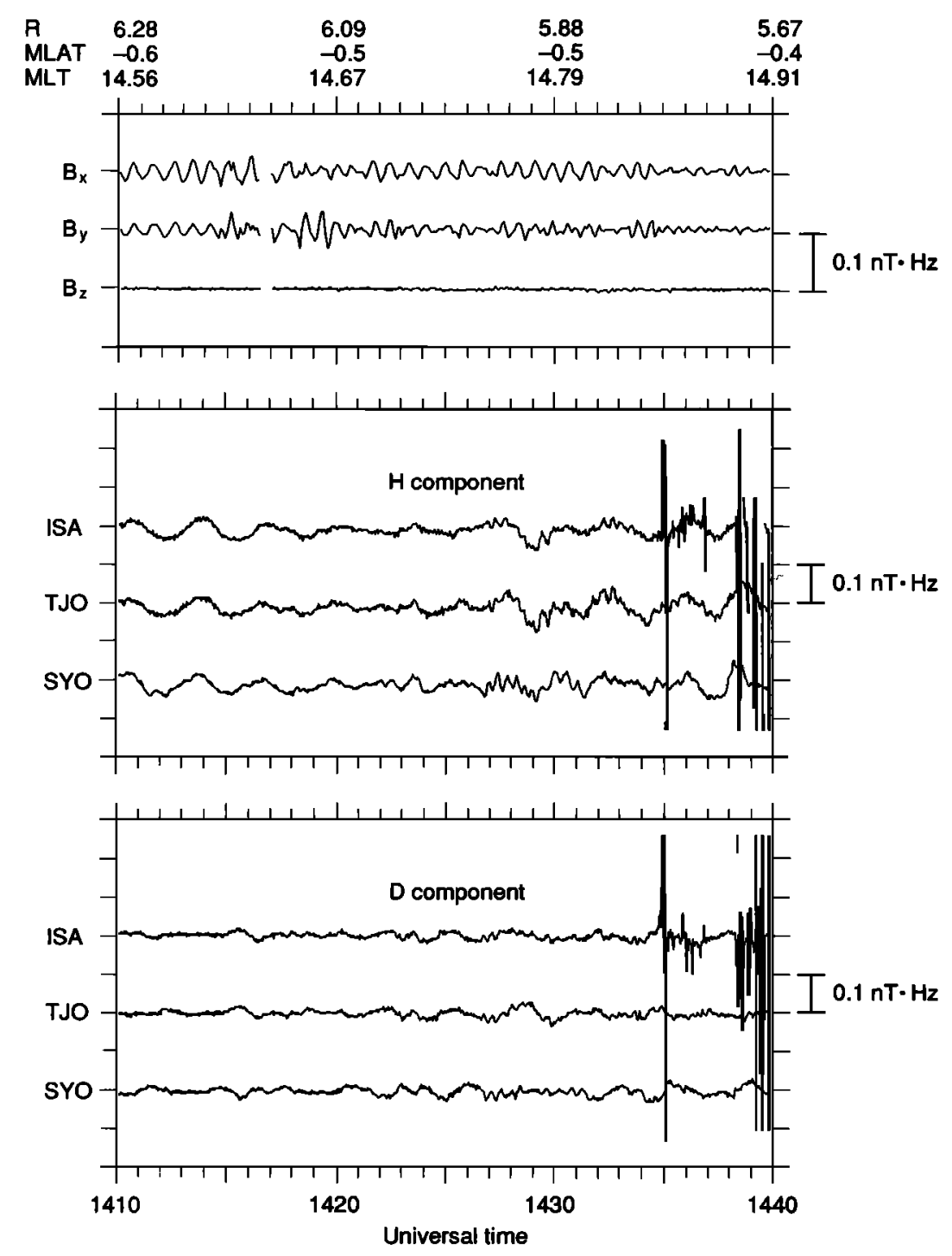

Fig. 3b. Same as Figure 3a except for Pc 4 event B. Ground records are available from three stations.

sations observed on the ground, with a special emphasis on a giant pulsation observed on February 20, 1985. In section 5 we discuss the results of the data analysis compared with previous observational studies and theoretical predictions.

\section{EXPERIMENTS}

The CCE spacecraft was in a low-inclination $\left(5^{\circ}\right)$ elliptical orbit with apogee of $8.8 R_{E}$, perigee of $1.2 R_{E}$ and an orbital period of 16 hours. The experimental details of the CCE magnetometer have been given by Potemra et al. [1985]. For the present study the original data sampled at 0.124-s intervals were averaged over the satellite spin period $(-5.8 \mathrm{~s})$ and were rotated into a local dipole field aligned system as described by Takahashi et al. [1990a]. In the local coordinate system, $e_{z}$ is parallel to the local model magnetic field calculated from an Earth-centered dipole, $e_{y}$ is perpendicular to the local dipole meridian and is directed eastward, and $e_{x}$ is perpendicular to both $e_{y}$ and $e_{z}$ and is directed outward. The data were time differenced and plotted in hourly segments for the regions covering from $L-2$ to $L-7$ and for the entire CCE mission pe- riod from August 1984 to January 1989. The differencing procedure is approximately equivalent to passing the magnetic field time series through a high-pass filter with a frequency response similar to that of induction magnetometers [Takahashi et al., 1990a].

Magnetic field data from stations in Antarctica and Iceland were used to search for giant pulsations. The data were acquired with three-component search coil magnetometers installed at Syowa in Antarctica and at Husafell, Isafjordur, and Tjomes in Iceland. Digital records from the magnetometers, sampled at 2-s intervals, are used in the present study. See Sato et al. [1984] for the details of the magnetometer experiments.

Data from the European Incoherent Scatter Radar (EISCAT) magnetometer cross are also used for one giant pulsation event. The EISCAT magnetometer cross consists of seven stations in northem Scandinavia. The instruments are digitally recording flux gate magnetometers with a resolution of $1 \mathrm{nT}$ and a sample rate of one per $20 \mathrm{~s}$ [Lühr et al., 1984]. Data shown here have been high-pass filtered with $a-3 \mathrm{~dB}$ cutoff at 
1984 December 20

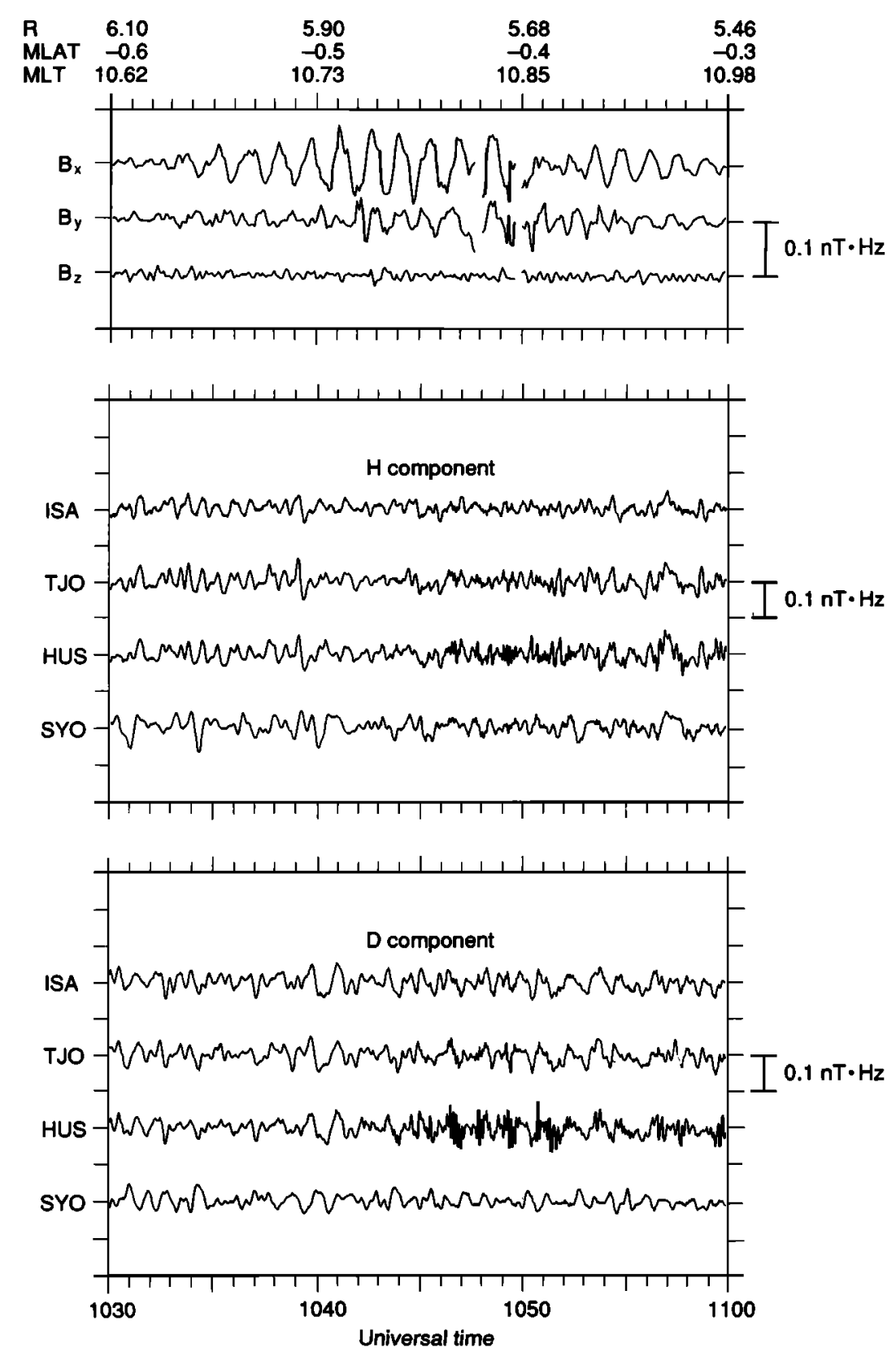

Fig. 3c. Same as Figure 3a except for Pc 4 event C. Ground records are available from four stations.

$300 \mathrm{~s}$. The magnetic local time of the stations is about 2.5 hours ahead of universal time (LT $=\mathrm{UT}+2.5)$.

The location of the ground stations are listed in Table 1. The geomagnetic coordinates are obtained using the definition of Baker and Wing [1989]. For the ground magnetic field records we use the usual geomagnetic $H D Z$ coordinates, wherc $H$ is the northward component, $D$ is the eastward component, and $Z$ is the vertical component.

\section{Transverse Pulsations at CCE}

In this section we examine whether equatorial transverse magnetic pulsations seen at CCE are observed as giant pulsations on the ground. In the first step of this analysis, we visually examined the hourly plots of the time-differenced CCE magnetic field data for transverse Pc 4 pulsations. We focused on the time intervals when the satellite was within $5^{\circ}$ of the dipole equator and was also close to Syowa and Iceland both in local time (within $\sim 1$ hours) and in $L$ (within $\sim 1 R_{E}$ ). From this survey we found six clear transverse Pc 4 events, which we call events A through $F$.

Figure 2 shows the location of the ground stations in Iceland and the CCE magnetic field foot points at the midpoints in time of the events as observed at CCE. The foot points, given at $100 \mathrm{~km}$ altitude, were determined using Tsyganenko's [1987] magnetic field model for $K p=0$. Two contours of constant magnetic latitude are also drawn using the geomagnetic coordinates of Baker and Wing [1989]. The CCE foot points are either in Iceland or in its immediate vicinity. All the foot 
1985 October 20

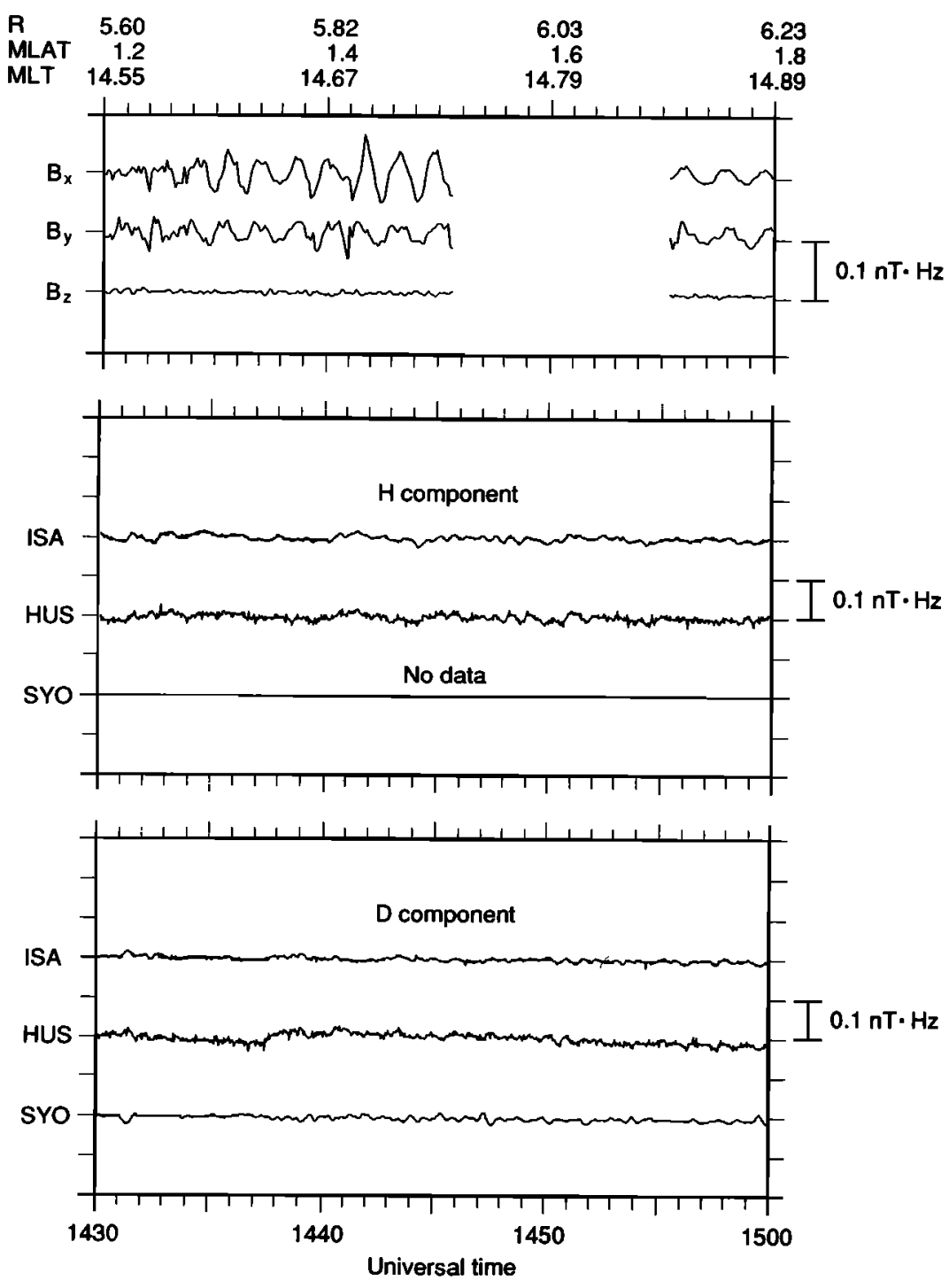

Fig. 3d. Same as Figure 3a except for Pc 4 event D. Ground records are available from three stations.

points were within $3^{\circ}$ of the center of the island in magnetic latitude and within $10^{\circ}$ in magnetic longitude.

Figures $3 a$ to $3 f$ show the magnetic field data for the six events. The magnetic field components at CCE are in the top panel and the magnetometer data from the Syowa and the three Iceland stations are in the middle and bottom panels respectively. The location of CCE is shown above the top panel. For CCE we plotted the time derivative $\left(B_{i+1}-B_{i}\right) / 2 \pi \Delta t$ of the original time series, where $B_{i}$ is the $i$ th data point and $\Delta t$ is the data sampling interval $(5.83 \mathrm{~s})$. This is done in order to make the CCE data compatible with the ground records. We can recover the amplitude of a magnetic pulsation (in nanoteslas) by dividing the amplitude (in nanotesla hertz) of the time derivative time series by the frequency (in hertz) of the pulsation. See Table 2 for the summary of the satellite location and wave properties.

At CCE all the events show an almost purely transverse oscillation, with a large amplitude in $B_{x}$ but also with an appreciable perturbation in $B_{y}$. Because the spacecraft was very close to the equator, with a dipole latitudes of less than $2^{\circ}$ for five events and $\sim 5^{\circ}$ for one event, we interpret the transverse nature of the pulsation as the consequence of an even-mode standing wave structure. Previous studies of similar events also concluded that radially polarized equatorial pulsations had an even mode structure, on the basis of their frequency [Singer et al., 1982], amplitude variation with latitude [Anderson et al., 1990], and the related ion flux modulations [Takahashi et al., 1990b].

From visual examination of the ground records in Figure 3 it is evident that there is no clear indication of a giant pulsation. A giant pulsation would have been detected as a highly sinusoidal oscillation in the $D$ component. To strengthen this statement we examine event $C$, which shows simultaneous pulsation activity at CCE and on the ground. We compare in Figure 4 the waveforms and power spectra of $B_{x}$ at $C C E$ and $D$ at HUS for this event. Although the oscillation on the ground contains strong spectral power in the Pc 4 band, its waveform is quite irregular in comparison with the Pc 4 pulsation in the magnetosphere, and its power spectrum does not exhibit a sharp spectral peak that is expected for a giant pulsation. The ground-satellite correlation for the other five events is far 
1987 May 26

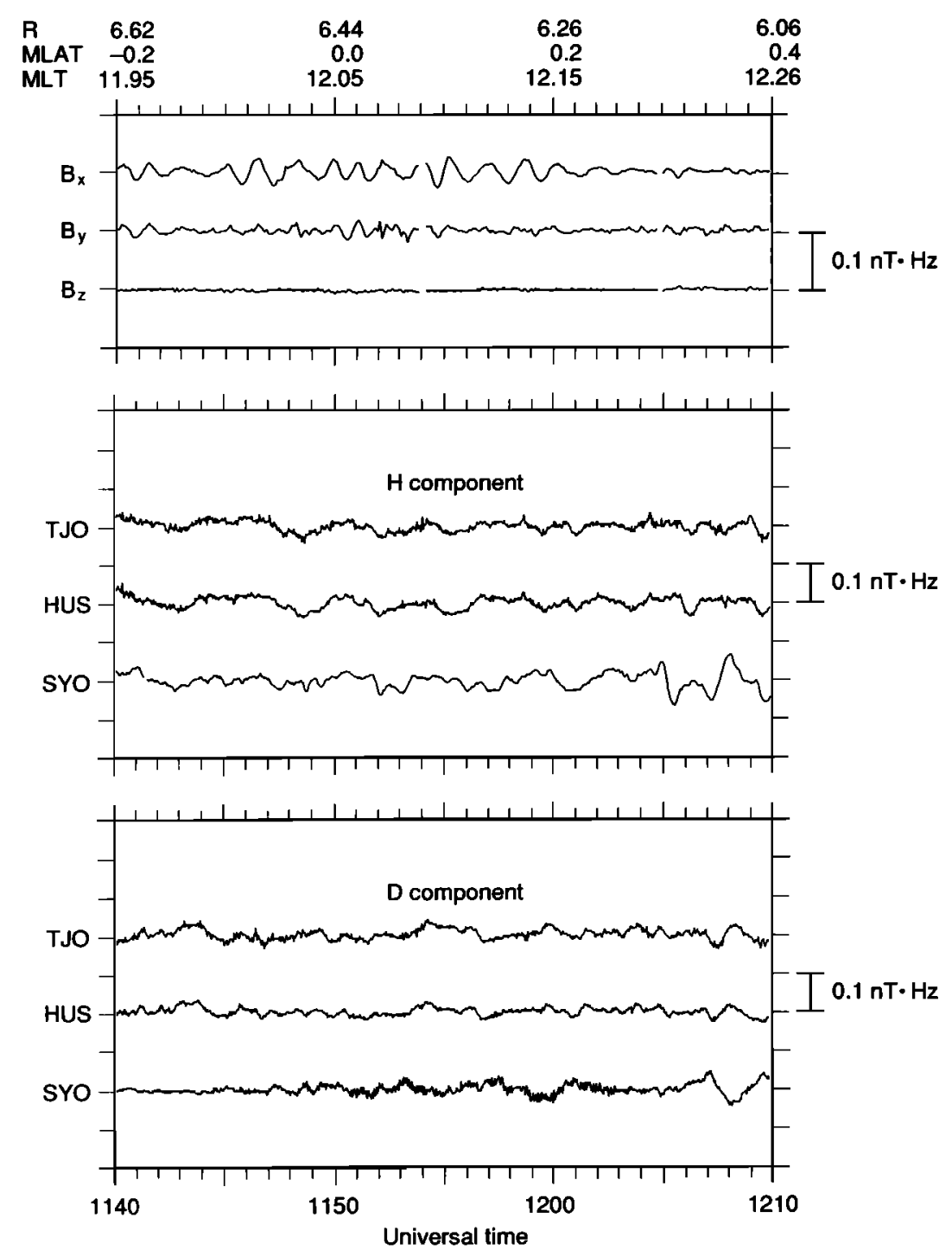

Fig. 3e. Same as Figure 3a except for Pc 4 event E. Ground records are available from three stations.

worse than this event. Therefore, we conclude that there is no evidence in our data set that even-mode standing waves are related to giant pulsations.

We believe that in each event the ground stations were sufficiently close to the CCE foot point to ensure detection of giant pulsations. Although giant pulsations are known to be highly localized in latitude, they still produce observable ground-level signals over $\sim 5^{\circ}$ of latitude [Veldkamp, 1960; Saito, 1969]. Because the foot points of CCE at the time center of each event was located within $3^{\circ}$ (in geomagnetic latitude) of at least one of the ground stations, any giant pulsation occurring on the CCE magnetic field line should have been observed at least at one station. This statement is not altered even when the CCE foot points are calculated for $K p>5$ instead of $K p=0$. For the higher $K p$ range the foot point is shifted to geomagnetic south only by 0.9 to $1.7^{\circ}$. Since all the transverse Pc 4 events were observed when $K p \leq 3$, the latitudes of the foot points probably did not differ from those illustrated in Figure 2 by more than $1^{\circ}$.

The null result of the above analysis is consistent with the general feature of radially polarized transverse magnetic pulsations known from previous studies. First of all, the waves tend to occur more often in the afternoon sector than in the morning sector [Arthur and McPherron, 1981; Takahashi and McPherron, 1984; Anderson et al., 1990]. This occurrence distribution is inconsistent with giant pulsations, which occur preferentially on the morning side [e.g., Green, 1979]. Second, the waves likely have a large azimuthal wave number, $m=O(100)$. Evidence for the wave number comes from multisatellite coherency analysis [Hughes et al., 1978] and from the analysis of ion flux oscillations associated with a magnetic pulsation [Takahashi et al., 1990b]. Because the ionosphere masks pulsations with such a large $m$ [Hughes and Southwood, 1976a,b], it would be surprising if the waves were detected on the ground. Similar arguments have been presented by Kokubun [1980] and by Kokubun et al. [1989] based on observations with geostationary satellites.

To summarize, no giant pulsations were observed on the ground during the time intervals when CCE observed a transverse Pc 4 wave near the geomagnetic equator and on the field 
1988 March 8

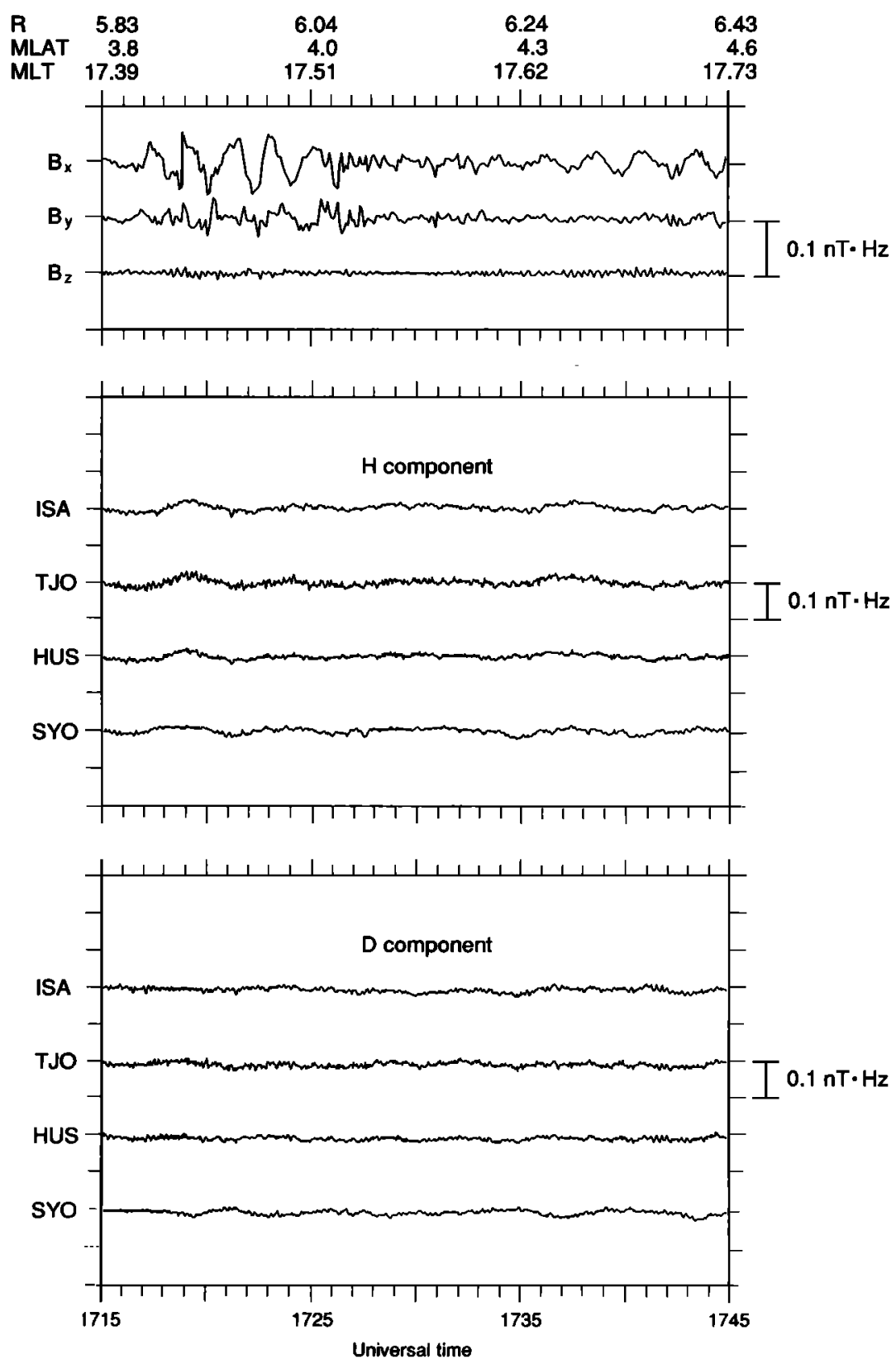

Fig. 3f. Same as Figure 3a except for Pc 4 event F. Ground records are available from four stations.

line nearly connected to the ground stations. This is strong evidence against the suggestion that second-harmonic standing Alfvén waves are the source of giant pulsations.

\section{Compressional Pulsations at CCE}

In an effort to find symmetric standing waves, we did a similar survey of compressional Pc 4 pulsations occurring near the magnetic equator and near the magnetic field lines connected to the Syowa and Iceland stations. Compared with transverse pulsations, the occurrence of nearly monochromatic and strongly compressional Pc 4 pulsations was found to be infrequent. Therefore we have relaxed the local time limits of the satellite to within $\sim 3$ hours of the ground stations while keeping the dipole latitude of the satellite within $5^{\circ}$ and $L$ shell within $1 R_{E}$ of the ground stations. One reason for the extended local time limits is the previous observation that giant pulsations can have a local time extent of 2 hours or longer [e.g., Veldkamp, 1960]. In this survey, five candidate Pc 4 events were found. Three of these had a corresponding pulsation signature on the ground, but only one event could be unambiguously identified as a giant pulsation from the ground records.

In the following subsections we will focus on the giant pulsation event, which occurred on February 20,1985. We will first demonstrate that the event on the ground was indeed a giant pulsation and then describe the pulsation properties at $\mathrm{CCE}$. The location of the CCE foot point and ground stations for the giant pulsation event are illustrated in Figure 5. At 1000 UT, the approximate time center of the giant pulsation, the magnetic local time was 7.2 hours at CCE, 9.8 hours at Iceland, and 12.2 hours at the EISCAT magnetometer cross. 
TABLE 2. Characteristics of Transverse Pc 4 Waves Observed From CCE

\begin{tabular}{|c|c|c|c|c|c|c|c|}
\hline Event & Date & $\begin{array}{l}\text { Time, } \\
\text { UT }\end{array}$ & $\begin{array}{l}R, * \\
R_{E}\end{array}$ & $\begin{array}{c}\text { MLAT, } \\
\text { deg }\end{array}$ & $\begin{array}{l}\text { MLT,* } \\
\text { hours }\end{array}$ & $\underset{n=}{B_{x} \text { Amplitude, }}$ & Period, \\
\hline $\mathbf{A}$ & Aug. 25, 1984 & 1610 & 6.2 & 0.8 & 16.2 & 2 & 48 \\
\hline B & Sept. 28, 1984 & 1420 & 6.1 & -0.5 & 14.7 & 0.5 & 49 \\
\hline C & Dec. 20,1984 & 1040 & 5.9 & -0.5 & 10.7 & 4 & 90 \\
\hline $\mathrm{D}$ & Oct 20,1985 & 1440 & 5.8 & 1.4 & 14.7 & 3 & 90 \\
\hline $\mathbf{E}$ & May 26, 1987 & 1150 & 6.4 & 0.0 & 12.1 & 2 & 93 \\
\hline $\mathbf{F}$ & Mar. 8, 1988 & 1720 & 5.9 & 3.9 & 17.4 & 5 & 120 \\
\hline
\end{tabular}

$\star R$, MLAT, and MLT are the geocentric distance, magnetic latiude, and the magnetic local time of the satellite.
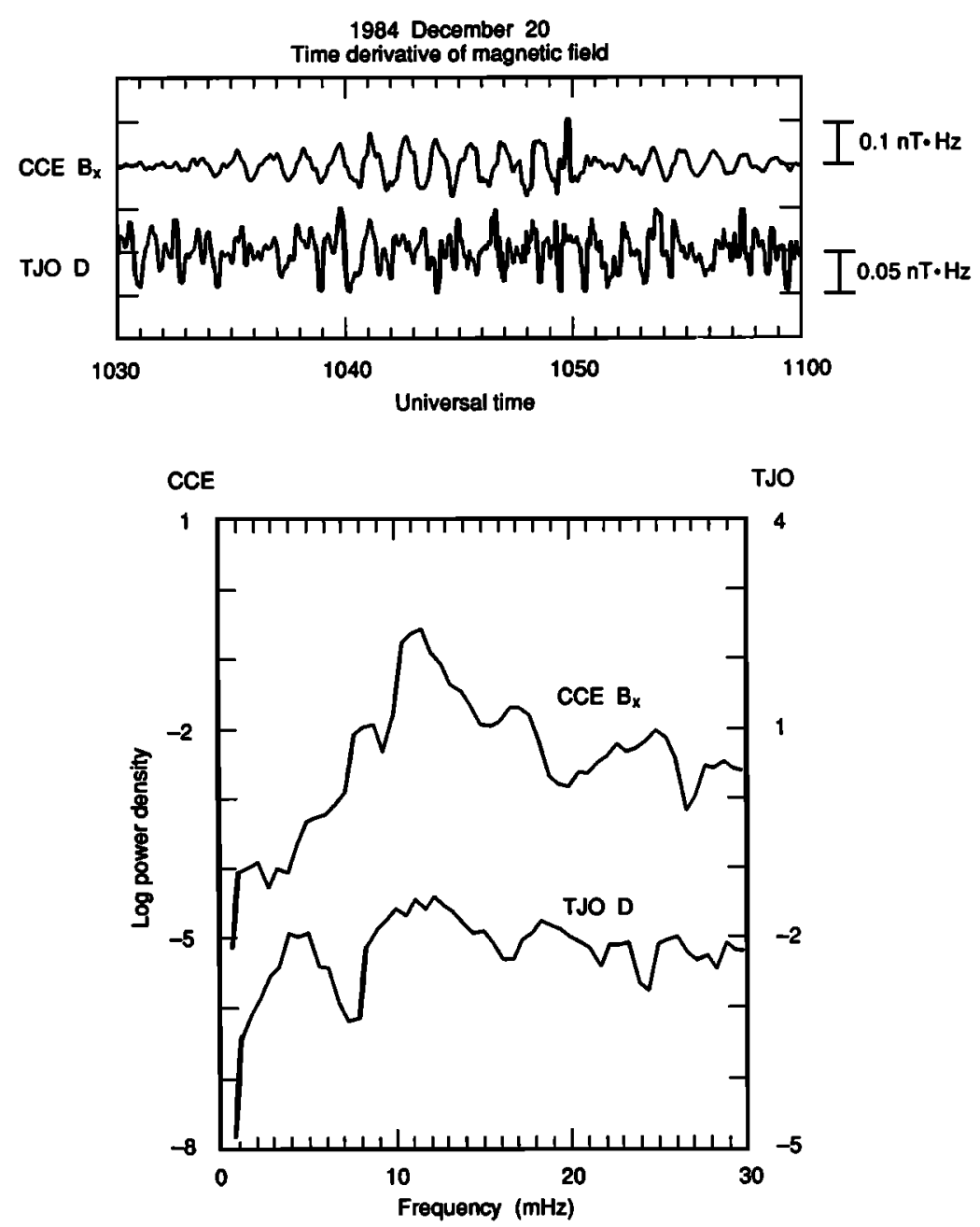

Fig. 4. Comparison of time series and power spectra of data from CCE and TJO for event C.

4.1. Geomagnetic Background for the February 20, 1985, Event

Figure 6 shows the $A E$ index for the 1-day interval including the giant pulsation event. The geomagnetic activity was fairly high throughout the first half of the day. The $K p$ index also showed a higher geomagnetic activity in the first half of the day. At 1000 UT the value of $K p$ was $2^{+}$. There was no satellite observation of the solar wind at the time of the giant pulsation.

Figure 7 shows the magnetic field and particle data [McEntire et al., 1985] from CCE. The pulsation event (indicated by vertical dashed lines) was preceded by moderately enhanced geomagnetic activity as seen in the ion injections at 0630 UT and 0800 UT. However, there is no evidence of local particle flux enhancement at the time of the pulsation. The pulsation event cannot be seen in these magnetic field data because they were averaged to 68 -s time resolution.

\subsection{Ground Magnetograms for the February 20, 1985, Event}

Waveform. Figures 8 and 9 show the magnetic field data from the ground stations. At the Syowa and Iceland stations (Figure 8) a giant pulsation is observed from 0940 to 1030 UT. 


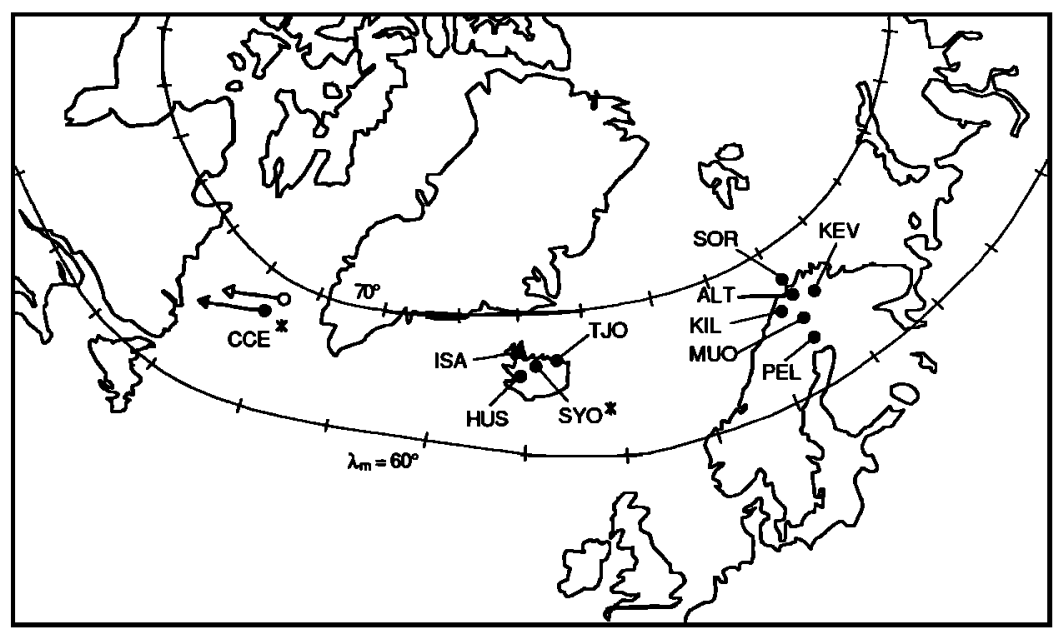

Fig. 5. Location of the CCE foot points and ground stations for the giant pulsation event on February 20, 1985. The format is the same as in Figure 1, except for additional stations of the EISCAT magnetometer cross. The conjugate point of SYO is also indicated by a solid circle marked SYO*. The arrows indicate the motion of the CCE foot points for the time interval 0900-1000 UT obtained from the Tsyganenko [1987] model field for the two activity levels $K p=0$ (open arrow) and $K p>$ 5 (solid arrow).

The average period of the oscillation is 90 seconds. The overall amplitude maximum (0.3 nT Hz, or $27 \mathrm{nT}$ peak to peak at 90-s period) occurred in $D$ of the lowest latitude station, HUS ( $L=$ 5.99). At the EISCAT magnetometer cross a similar pulsation is observed. Because the EISCAT stations are located about $30^{\circ}$ east of Iceland, the data imply that the pulsation was extended at least $30^{\circ}$ in longitude. The amplitude is larger in $D$ than in $H$, especially at PEL where the amplitude is maximized.

Latitude dependence of amplitude and ellipticity. Figure 10 shows the latitude profile of the power spectral density and the ellipticity of the pulsation signal calculated separately for the EISCAT and Iceland station groups. The spectral density is represented by the trace of the horizontal power, which is normalized to the maximum power observed in each set of the stations. The ellipticity is defined in such a manner that 1 means clockwise circular polarization on the horizontal plane as viewed from above, 0 means linear polarization, and -1 means counterclockwise circular polarization. These spectral parameters are evaluated at the frequency center, $11 \mathrm{mHz}$, of the pulsation signal. The power density is highest near $63^{\circ}(\mathrm{L} \sim 4.9)$ and at this latitude the sign of the ellipticity changes from negative at lower latitudes to positive at higher latitudes. These features are consistent with previous multistation observations of giant pulsations [Rostoker et al., 1979; Glassmeier, 1980; Hillebrand et al., 1982; Chisham et al., 1990].

Azimuthal wave number. Using multiple ground stations, we can determine the azimuthal wave number of the pulsation. Since we do not have stations located at exactly the same latitude, we need to take into account a possible latitudinal phase variation in evaluating the azimuthal wave number. As a simple approach to this problem we adopt a method used by Tonegawa and Sato [1987]. In that method the phase of a pulsation signal is assumed to change linearly both in latitude $\left(\lambda_{m}\right)$ and in longitude $\left(\phi_{m}\right)$, i.e., as $\exp \left[i\left(\lambda_{m}+m \phi_{m}\right)\right]$. The horizontal phase variation is then determined by solving the equation

$$
\Phi_{j}-\Phi_{i}=\boldsymbol{x} \cdot\left(\mathbf{r}_{j}-\mathbf{r}_{i}\right)
$$

where $\Phi$ is the phase of the oscillation in a magnetic field component $(H$ or $D), \kappa=(l, m)$ is the dimensionless horizontal wave vector, and $r=\left(\lambda_{m}, \phi_{m}\right)$ gives the geomagnetic latitude and the longitude of a station. The subscripts, $i$ and $j$ designate a station pair. For each of the magnetic field components, data from three stations yield a unique value of $\alpha$ because equation (1) gives three scalar equations but only two of them are independent.

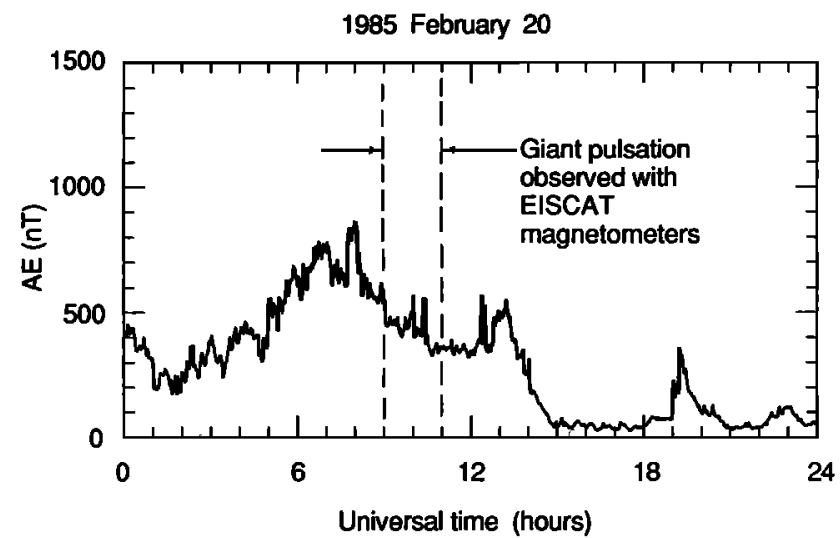

Fig. 6. AE index for a 1-day interval including the giant pulsation event on February 20, 1985. 


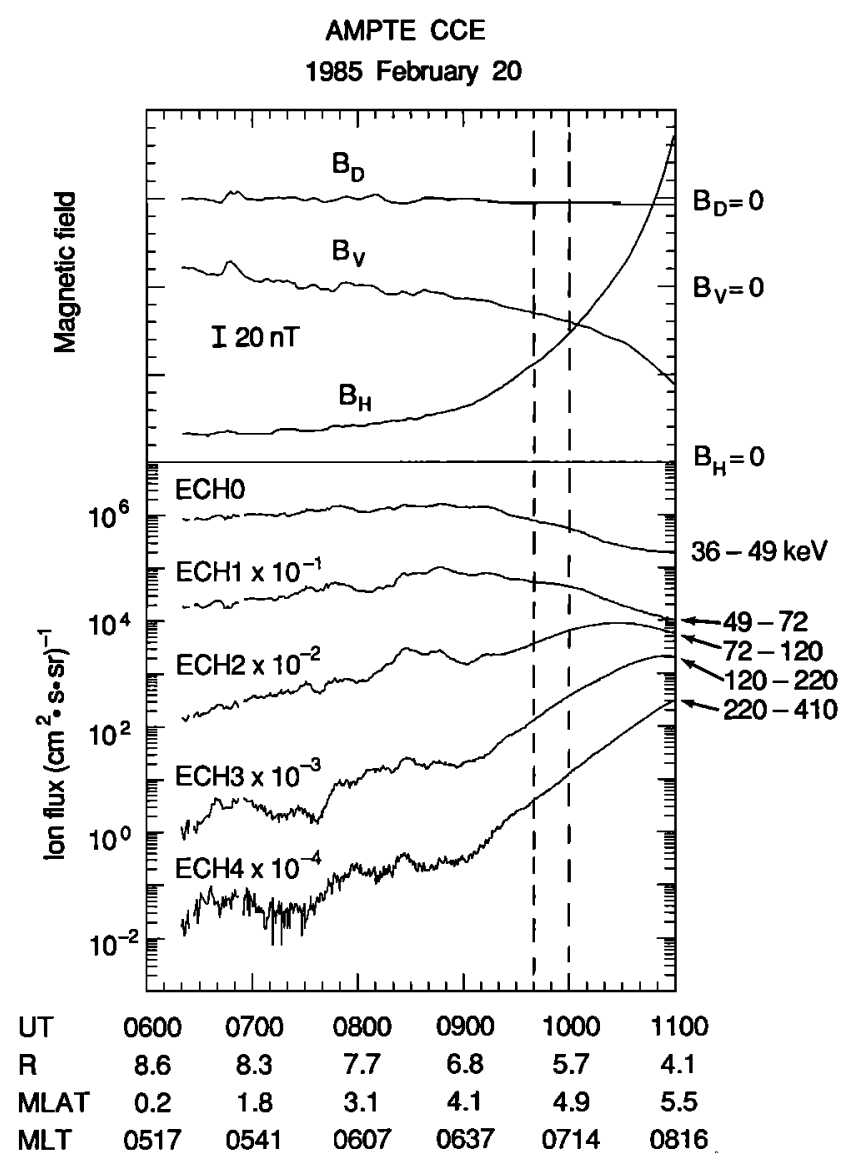

Fig. 7. Magnetic field and ion fluxes measured from CCE for a time interval including the giant pulsation event on February 20, 1985. The particle fluxes were measured by the ion head of the Medium Energy Particle Analyzer [McEntire et al.. 1985]. The magnetic field data are 68-s averages and the particle data are averaged over four spins ( $-24 \mathrm{~s})$ of the satellite.

Since pulsation signals do not in general represent a plane wave, caution must be exercised in interpreting the "wave numbers" derived from this equation. That is, the latitudinal wave number is likely related to a latitudinal field line resonance structure [e.g., Hughes and Southwood, 1976b], which does not in general exhibit a linear phase variation. Also, the latitudinal phase variation may differ for different magnetic field components. On the other hand, because pulsation signals very likely propagate azimuthally, the azimuthal wave number derived from (1) would have the usual meaning for a propagating wave.

We have calculated the value of $l$ and $m$ from the relative phase of the $D$ component pulsation seen at the three stations in Iceland and also at the three stations KIL, ALT, and KEV in the EISCAT magnetometer cross. All these stations were located northward of the inferred latitude of the amplitude maximum. The time interval used is 0950-1010 UT for the Iceland stations and 0940-1020 UT for the EISCAT stations. The magnetic records from the station at the intermediate longitude (HUS in Iceland and ALT in the EISCAT magnetometer cross) were used as reference time series, and the phase lag was defined within the range of $-180^{\circ}$ to $180^{\circ}$. The phase lag was estimated at the frequency, $11 \mathrm{mHz}$, of the giant pulsation, using the standard fast Fourier transform of two-component time series [Bendat and Piersol, 1971]. We used smoothed cross spectra (number of degrees of freedom $=6$ ) throughout. For the
Syowa and Iceland induction magnetometers 1985 February 20

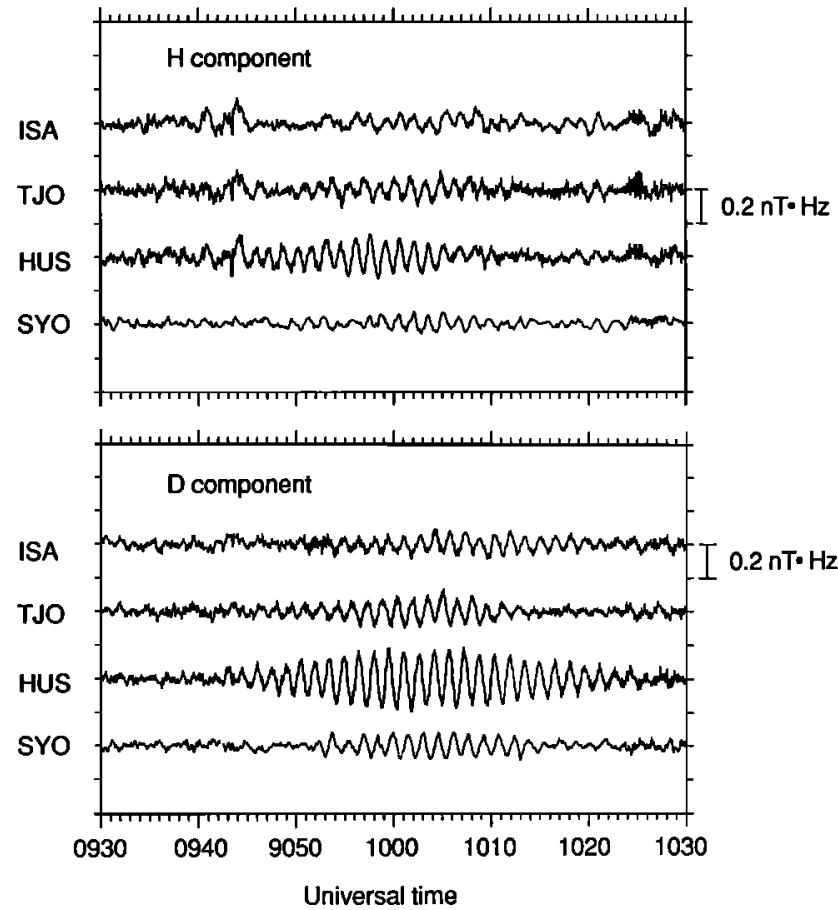

Fig. 8. Magnetic field variations observed by induction magnetomelers at three stations in Iceland and at the Syowa station in Antarctica for the giant pulsation event on February 20,1985. The data are plotued in 2-s intervals.

former station group we obtained $l=-4$ and $m=-36$ and for the latter $l=7$ and $m=-25$, where the negative sign means southward phase propagation for $l$ and westward phase propagation for $m$.

The small values of $l$ mean a slow latitudinal phase variation, which has been observed previously [e.g., Glassmeier, 1980]. The sign and the magnitude of $m$ are also consistent with previous observations [Rostoker et al., 1979; Glassmeier, 1980; Hillebrand et al., 1982; Poulter et al., 1983; Chisham et al., 1990], although an azimuthal wave number of -36 appears to be at the higher end of previously observed values. The different azimuthal numbers obtained from the two station sets imply that the wavelengh of the pulsation varied with longitude, because the pulsation periods were almost identical at the two locations.

To summarize the ground observations, the Pc 4 pulsation observed on February 20, 1985 had the properties of a giant pulsation.

\subsection{CCE Magnetic Field Data for the February 20, 1985, Event}

Figure 11 shows the magnetic field data from $\mathrm{CCE}$ along with selected ground stations. Both the raw magnetic field record and its time derivative are shown for CCE. From 0940 to 1000 UT a strongly compressional oscillation was present at CCE. Its period is $88 \mathrm{~s}$, which is in exact agreement with the period observed at the Syowa and Iceland stations for the same interval. The amplitude is 1-2 nT peak to peak, which is smaller than the $D$ component amplitude on the ground by a factor of 10-20.

The time series plots and power spectra of the CCE $B_{2}$ component and the HUS $D$ component are shown in Figure 12. 


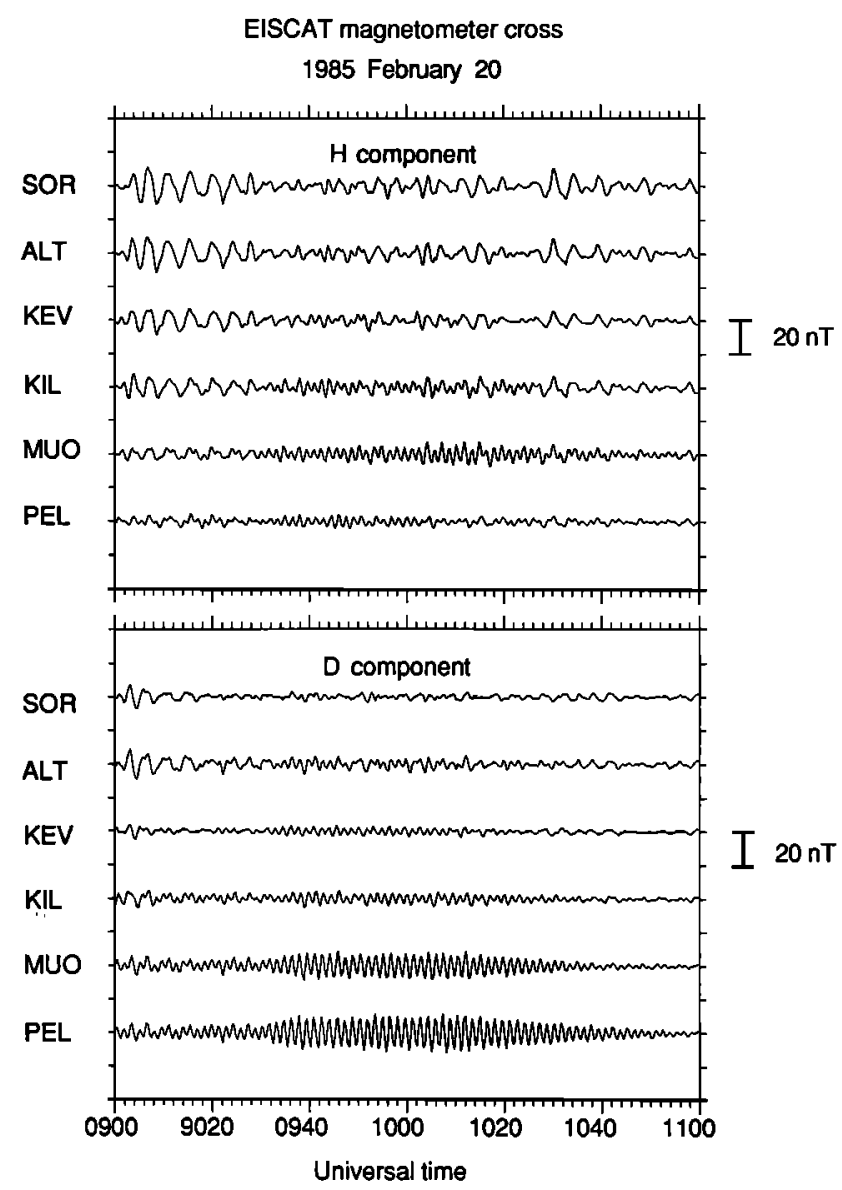

Fig. 9. Magnetic field variations observed by flux gate magnetometers at six EISCAT magnetometer cross stations for the giant pulsation event on February 20, 1985. The data have been high-pass filtered with a cutoff of $-3 \mathrm{~dB}$ at $300 \mathrm{~s}$ and are plotted in 20-s intervals.

Note that the spectral peaks of the oscillations occur at the same frequency at the two locations and that the relative phase of the oscillations is maintained constant for the 25-min interval illustrated. On the basis of this high degree of correlation we conclude that the spacecraft and the ground station observed the same phenomenon even though the observing points were separated by 2.6 hours in magnetic local time. Most importantly, since the spacecraft was only $4.7^{\circ}$ north of the dipole equator, we conclude that the strong compressional component is the consequence of an odd-mode standing wave.

Our observation is consistent with that made by Hillebrand et al. [1982]. They showed that the magnetospheric signal corresponding to a well-defined giant pulsation on the ground was a strongly compressional magnetic perturbation with a period of $90 \mathrm{~s}$ and a peak-to-peak amplitude of 1-2 nT, all quite similar to the February 20,1985, event observed from CCE. Also the location of their satellite (ATS-6), $R \sim 6.6 R_{E}$ MLAT $\sim-5^{\circ}$, and MLT $\sim 6$ hours, was very close to that of ours, $R \sim 6 R_{E}$, MLAT $\sim-5^{\circ}$, and MLT -7 hours. This similarity in satellite observations, combined with the null results obtained in section 3 , gives us a very strong basis for suggesting that giant pulsations as seen in the magnetosphere and near the magnetic equator are a small-amplitude $(\Delta B / B \sim 1 \%)$ compressional pulsation, rather than a transverse pulsation. If the pulsations have a standing wave structure along the geomagnetic field lines, then the presence of almost purely compressional oscillations to-
Giant pulsation on February 20, 1985
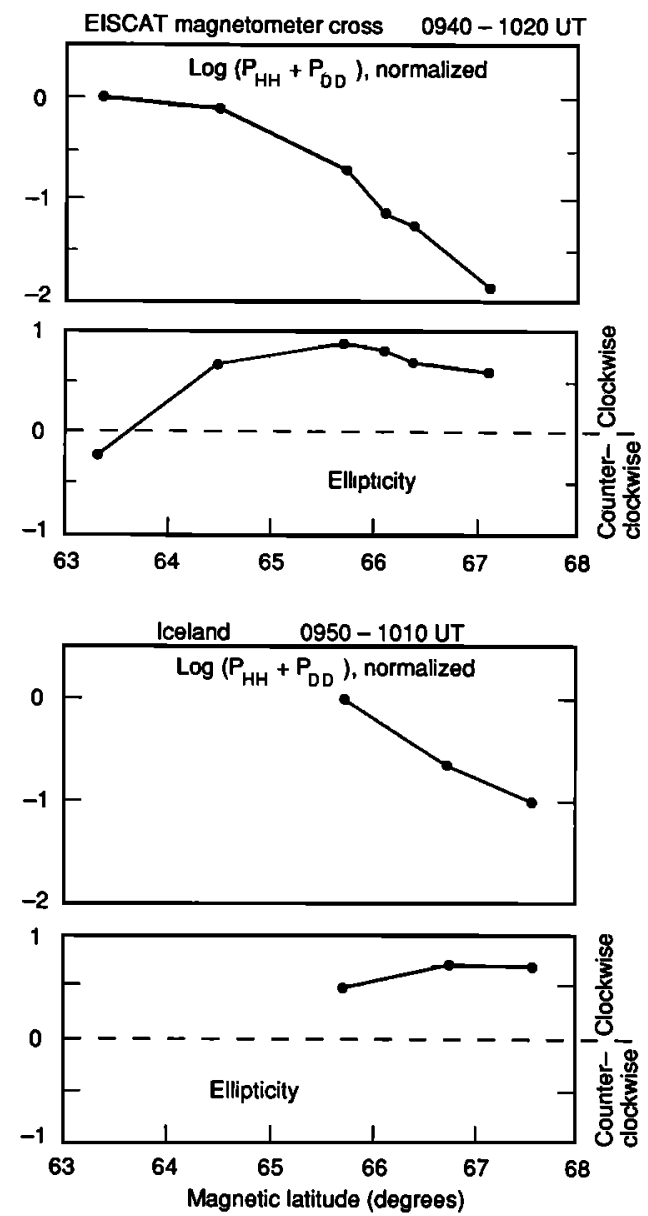

Fig. 10. Latitude dependence of the intensity and ellipticity of the horizontal magnetic field oscillations as observed (top) at EISCAT magnetometer cross and (bottom) at Iceland. The horizontal power spectral density $\left(P_{\mathrm{HH}}+P_{\mathrm{DD}}\right)$ is normalized to the maximum value in each station group.

gether with the lack of transverse oscillations implies an oddmode structure.

\section{Discussion}

In this section we compare our results with previous results and discuss possible generation mechanisms of giant pulsations.

\subsection{North-South Conjugacy}

Our conclusion is in conflict with some ground-based observations of the harmonic mode of giant pulsations. We would like to comment on whether reliable results can be obtained from conjugate ground observations. If the stations are in exact conjugacy it is easy to determine the mode: for an odd-mode wave there will be a $180^{\circ}$ north-south phase lag in $D$, while for an even-mode wave there will be no phase lag. In reality, however, stations are not in exact conjugacy, and because the phase of a giant pulsation changes with longitude, one has to be careful in discussing the north-south phase lag. If we take the azimuthal wave number of -36 as was measured at Iceland for the February 20, 1985, giant pulsation, the phase changes $360^{\circ}$ over a longitudinal distance of $10^{\circ}$. Therefore, in order to deduce a correct standing wave mode without compensating for the azimuthal phase variation, one needs to have stations separated by less than $25^{\circ}$, which corresponds to a phase lag of 


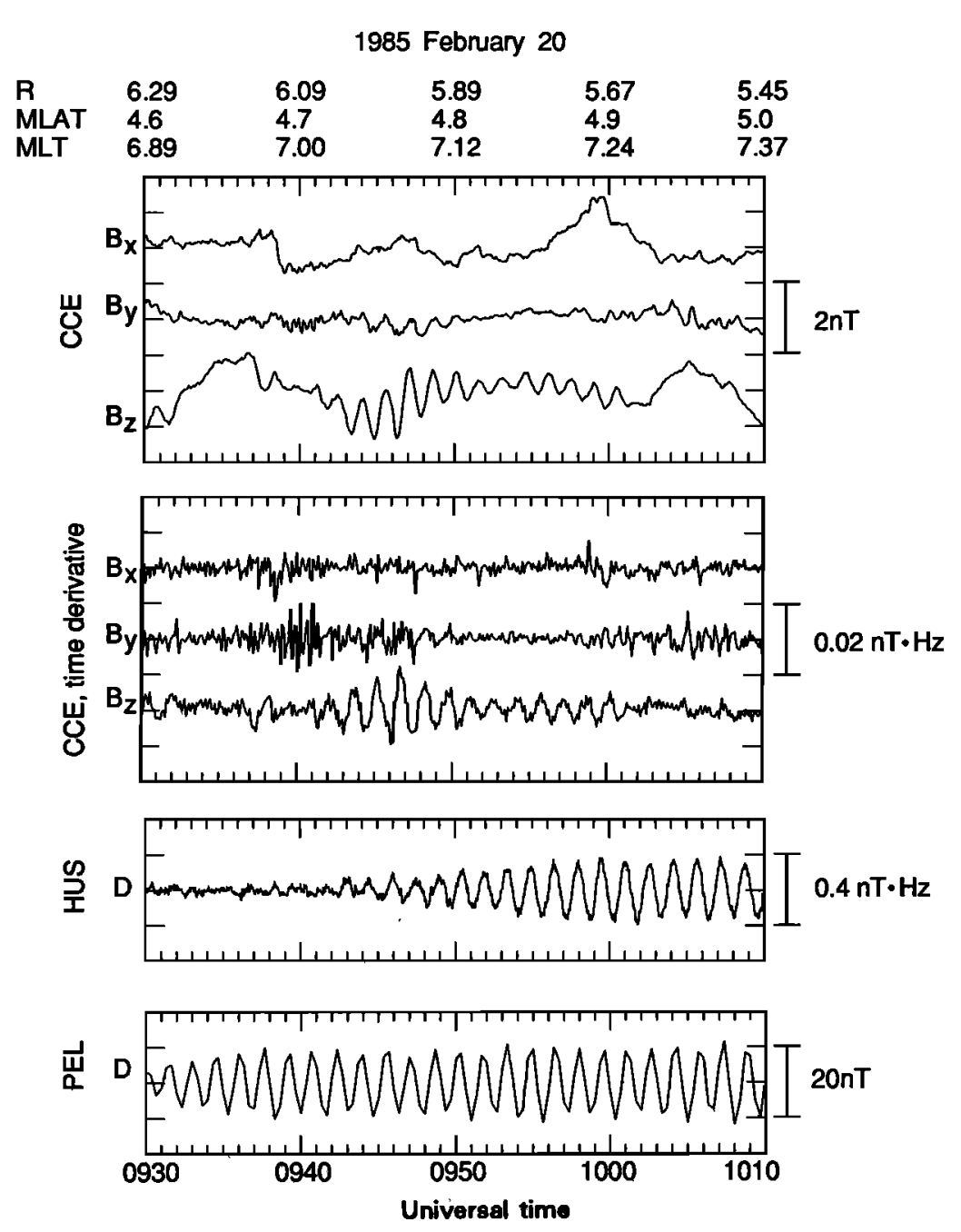

Fig. 11. Comparison of magnetic field data from CCE and selected ground stations for the giant pulsation event on February 20, 1985. To make ground-satellite comparison easy, both the raw time series and its time derivative are shown for CCE.

90. In previous studies, Annexstad and Wilson [1968] used College and Macquarie (separated by $13^{\circ}$ in geomagnetic longitude) to infer that a giant pulsation had an even-mode structure, while Green [1979] used St Anthony and Halley Bay (separated by $5^{\circ}$ ) to infer that two giant pulsations had an odd-mode structure. In neither study was azimuthal phase variation taken into account. On the basis of our aforementioned consideration, we conclude that the degree of conjugacy between the stations was not high enough for the determination of the harmonic mode of giant pulsations and that it is not surprising that the two studies obtained conflicting results.

Another matter of concern is the distortion of geomagnetic field lines by magnetospheric currents. The conjugacy of stations are usually discussed using internal magnetic field models, but to be precise one needs to evaluate the contribution of external currents. According to the International Geomagnetic Reference Field (IGRF) (1985) model, the conjugate point of SYO during the giant pulsation event was located geomagnetically $2.1^{\circ}$ east of HUS. However, using the Tsyganenko [1987] model we find that the conjugate point was $0.8^{\circ}$ east of HUS for $K p=0$ and $1.7^{\circ}$ west of HUS for $K p>5$. This means that the discrepancy among the conjugate points from various models can be as large as $-4^{\circ}$ in longitude. This result implies that even if one had a perfectly conjugate pair of stations in terms of the internal magnetic field, the extemal fields could shift the location of the conjugate point to such a degree that it is not possible to determine the harmonic mode of giant pulsations from conjugate observations.

\subsection{Plasma Density and Pulsation Periods}

Chisham and Orr [1991] discussed the relation between the period of giant pulsations and expected ranges of equatorial mass densities and came to the conclusion that the pulsations had a period corresponding to the second-harmonic standing Alfvén waves. If the giant pulsations observed at $L=6-8$ had an odd-mode (fundamental) structure, then the equatorial mass density needed to be about 1 order of magnitude lower than that expected.

We would like to make two comments on their analysis. One is that the range of the mass densities was estimated from the observed periods of pulsations [Poulter et al., 1984] which were not giant pulsations. Therefore, the density range does not necessarily reflect the geomagnetic condition under which giant pulsations are excited. Giant pulsations are a rare phenomenon, so the equatorial mass density might be unusually low when giant pulsations are excited. We emphasize that there has been no in situ measurement of the mass density during a giant pulsation event. 

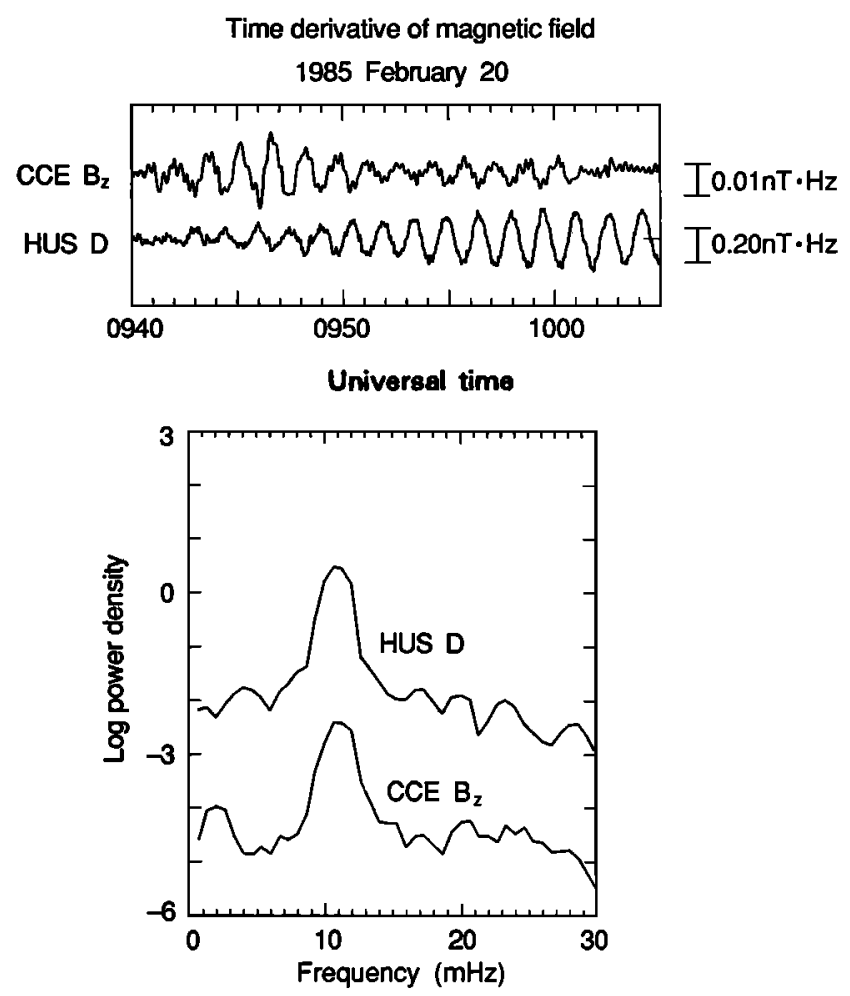

Fig. 12. Satellite-ground comparison of magnetic field data for the giant pulsation on February 20, 1985.

Another comment is that the pulsation periods of Chisham and Orr [1991] do not exclude the possibility of third-harmonic standing waves. Since the frequency ratio of the third harmonic to the second harmonic is roughly 1.6 [Cummings et al., 1969], the equatorial density corresponding to the assumption of a third harmonic is only by a factor of $2.6\left(=1.6^{2}\right)$ higher than the density corresponding to the assumption of a second harmonic. Equatorial mass densities higher by this factor are within the allowed range as discussed by Chisham and Orr.

There is some evidence supporting the third-harmonic standing wave structure for the February 20 event. In the records from the EISCAT magnetometer cross (Figure 9), the $H$ component shows a Pc 5 pulsation from 0900 to 0930 UT. Note that in this time interval the giant pulsation was already present (see the $D$ component variation at PEL), implying that two waves from different origins coexisted on the same field line. From the strong north-south perturbation of the Pc 5 oscillation we suggest that it was a standing Alfvén wave excited by an external source. If that is the case, then it is most likely that the wave was a fundamental mode and its period, $200-300 \mathrm{~s}$, implies that the giant pulsation (period $\sim 90 \mathrm{~s}$ ) was excited at the third harmonic. Note that a fundamental period around 300 $s$ has often been observed at $L=6-7$, for example with the STARE (Scandinavian twin auroral radar experiment) radar [Walker et al., 1979] and with the GEOS 2 electric field experiment [Junginger et al., 1984].

\subsection{Excitation Mechanism for Giant Pulsations}

Brief comments are made here on previously suggested generation mechanisms for giant pulsations.

Ion resonance with standing Alfuén waves. Energetic ions in the ring current can excite standing Alfvén waves through drift bounce resonances

$$
\omega-m \omega_{d}=N \omega_{b}
$$

where $\omega$ is the frequency of a standing wave, $\omega_{d}$ and $\omega_{b}$ are the magnetic drift and bounce frequencies of trapped ions, and $N$ is an integer. Theoretical analyses indicated that an instability most likely generates an even-mode standing wave through the $N= \pm 1$ resonances [Southwood, 1976; Chen and Hasegawa, 1988, 1991]. This mechanism has been suggested to be applicable to giant pulsations [Glassmeier, 1980; Poulter et al., 1983; Glassmeier et al., 1990; Chisham et al., 1990; Chisham and Orr, 1991]. However, we conclude that this is not the case because our observations indicate that giant pulsations are oddmode standing waves. If the resonant excitation is applicable to odd-mode standing waves, then the resonance must occur at an even $N$.

Drift wave instability. Green [1979, 1985] suggested the drift wave instability of a compressional mode [Hasegawa, 1971] as a source for giant pulsations. The instability is excited in a plasma with mixed cold and hot components such as in the plasmasphere. In Hasegawa's theory a slab geometry was used and no consideration was given to the coupling of the mode to a standing Alfven wave. However, Cheng and Lin [1987] discussed the compressional mode using a realistic field geometry and concluded that the compressional mode has an odd-mode standing wave structure. Therefore, the drift wave instability remains a candidate for the origin of giant pulsations.

\section{Concusion}

We have used satellite observations to determine the standing wave mode of giant pulsations. Our method is simply to examine whether the transverse (or compressional) magnetic field component has a node at the magnetic equator. This is the most direct and reliable method for determining the harmonic 
mode. Although we were able to positively determine the harmonic mode to be odd for only one giant pulsation event, the null result for even-mode waves substantially strengthens our conclusion that giant pulsations are in general an odd-mode standing wave. One important consequence is that the $N= \pm 1$ drift bounce resonance cannot be applied to giant pulsations. While second-harmonic standing Alfvén waves are quite often observed from spacecraft and they are likely generated by the $N= \pm 1$ resonance mechanism [Takahashi et al., 1990b], these waves are not the source of giant pulsations observed on the ground. If one wishes to apply drift bounce resonance to giant pulsations one needs to consider the $N=0, \pm 2$, resonances. Of course, other mechanisms including the drift wave instability were not eliminated from our analysis, and they require further analysis. Tests of various generation mechanisms using CCE particle data [Shelley et al., 1985; Gloeckler et al., 1985] will be an interesting subject for the future work.

Acknowledgments. One of the authors (K.T.) is grateful to D. On and D. Simmons for their help in the search for giant pulsations and to K. Baker for his help in calculating geomagnetic coordinates; he is also grateful to L. Chen and R. Sheldon for valuable comments and to B. Anderson for carefully reading the final draft. The EISCAT magnetometer cross is a joint enterprise of the Finnish Meteorological Institute, the Sodankyli Geophysical Observatory, and the Technical University of Braunschweig. The AE index was provided by the Data Analysis Center for Geomagnetism and Space Magnetism, Kyoto University. The particle data used in Figure 7 were made available by the effort of the CCE particle experimenters (R. McEntire, principal investigator). Work at The Johns Hopkins University Applied Physics Laboratory was supported by NASA under Task I of Navy contract N00039-89-5301 and by NSF. The work performed at the Aerospace Corporation was supported by the U.S. Air Force System Command's Space System Division under contract F04701-88-C-0089.

The Editor thanks C. A. Green and J. C. Samson for their assistance in evaluating this paper.

\section{REFERENCES}

Anderson, B. J., M. J. Engebretson, S. P. Rounds, L. J. Zaneut, and T. A. Potemra, A statistical study of Pc 3-5 pulsations observed by the AMPTE/CCE magnetic fields experiment, 1, Occurrence distributions, J. Geophys. Res., 95, 10,495, 1990.

Annexstad, J. O., and C. R. Wilson, Characteristics of Pg micropulsations at conjugate points, J. Geophys. Res., 73, 1805, 1968.

Arthur, C. W., and R. L. McPherron, The statistical character of Pc 4 magnetic pulsations at synchronous orbit, J. Geophys. Res., 86, $1325,1981$.

Baker, K. B., and S. Wing, A new magnetic coordinate system for conjugate studies at high latitudes, J. Geophys. Res., 94, 9139, 1989.

Barfield, J. N., L. J. Lanzerotui, C. G. Maclennan, G, A. Paulikas, and M. Schulz, Quiettime observation of a coherent compressional Pc-4 micropulsation at synchronous altitude, J. Geophys. Res., 76, 5252 , 1971.

Bendat, J. S., and A. G. Piersol, Random Data: Analysis and Measurement Procedures, p. 202, John Wiley, New York, 1971.

Birkeland, K., Expédition Norvégienne de 1899-1900 pour l'étude des aurores boréales. Résultats des recherches magnétiques, Videnskabsselsk. Skr., I. Mat. Naturvidensk. K., I, 1, 1901.

Chen, $L$, and A. Hasegawa, A theory of long-period magnetic pulsations, 1, Steady state excitation of field line resonance, J. Geophys. Res., 79, 1024, 1974.

Chen, $L$, and A. Hasegawa, On magnetospheric hydromagnetic waves excited by energetic ring-current particles, J. Geophys. Res., 93, 8763, 1988.

Chen, L, and A. Hasegawa, Kinetic theory of geomagnetic pulsations, 1, Intemal excitations by energetic particles, J. Geophys. Res., 96, $1503,1991$.

Cheng, C. Z., and C. S. Lin, Eigenmode analysis of compressional waves in the magnetosphere, Geophys. Res. Lett., 14, 884, 1987.
Chisham, G., and D. Orr, Statistical studies of giant pulsations (Pgs): Harmonic mode, Planet. Space Sci., 39, 999, 1991.

Chisham, G., D. Orr, M. J. Taylor, and H. Lühr, The magnetic and optical signature of a $\mathrm{Pg}$ pulsation, Planet. Space Sci., 38, 1443, 1990.

Cummings, W. D., R. J. O'Sullivan, and P. J. Coleman, Jr., Standing Alfven waves in the magnetosphere, $J$. Geophys. Res., 74, 778, 1969.

Glassmeier, K.-H., Magnetometer array observations of a giant pulsation event, J. Geophys., 48, 127, 1980.

Glassmeier, K.-H., M. V. Seggem, and A. Korth, Proton bounce-resonance instability as a possible generation mechanism of geomagnetic giant pulsation (abstract), Eos Trans. AGU, 71, 1528, 1990.

Gloeckler, G., F. M. Ipavich, W. Studemann, B. Wilken, D. C. Hamilton, G. Kremser, D. Hovestadt, F. Gliem, R. A. Lundgren, W. Riek, E. O. Tums, J. C. Cain, L. S. Masung, W. Weiss, and P. Winterhof, The charge-energy-mass spectrometer for $0.3-300 \mathrm{keV} / \mathrm{e}$ ions on the AMPTE CCE, IEEE Trans. Geosci. Remole Sens., GE$23,234,1985$.

Green, C. A., Observations of $\mathrm{Pg}$ pulsations in the northern auroral zone and at lower latitude conjugate regions, Planet. Space Sci., 27. 63, 1979.

Green, C. A., Giant pulsations in the plasmasphere, Planet. Space Sci., 33, 1155, 1985.

Hasegawa, A., Drift-wave instabilities of a compressional mode in a high- $\beta$ plasma, Phys. Rev. Lell., 27, 11, 1971.

Hillebrand, O., J. Münch, and R. L. McPherron, Ground-satellite correlative study of a giant pulsation event, J. Geophys., S1, 129, 1982.

Hughes, W. J., and D. J. Southwood, The screening of micropulsation signals by the atmosphere and ionosphere, J. Geophys. Res., 81, 3234, $1976 a$.

Hughes, W. J., and D. J. Southwood, An illustration of modification of geomagnetic pulsation structure by the ionosphere, J. Geophys. Res., 81, 3241, 1976b.

Hughes, W. J., R. L. McPherron, and J. N. Barfield, Geomagnetic pulsations observed simultaneously on three geostationary satellites, $J$. Geophys. Res., 83, 1109, 1978.

Junginger, H., G. Geiger, G. Haerendel, F. Melzner, E. Amata, and B. Higel, A statistical study of dayside magnetospheric electric field fluctuations with periods between 150 and 600 s, J. Geophys. Res., 89, 5495, 1984.

Kokubun, S., Observations of Pc pulsations in the magnetosphere: Satellite-ground correlation, J. Geomagn. Geoelectr., 32, suppl. II, SII 7. 1980.

Kokubun, S., K. N. Erickson, T. A. Fritz, and R. L. McPherron, Local time asymmetry of Pc 4-5 pulsations and associated particle modulations at synchronous orbit, J. Geophys. Res., 94, 6607, 1989.

Lanzerotti, L. J., and N. A. Tartaglia, Propagation of a magnetospheric compressional wave to the ground, J. Geophys. Res., 77, 1934, 1972.

Lee, D.-H., and R. L. Lysak, Effects of azimuthal asymmetry on ULF waves in the dipole magnetosphere, Geophys. Res. Lell., 17, 53, 1990.

Lühr, H., S. Thürey, and N. Klöcker, The EISCAT magnetometer cross, Geophys. Surv., 6, 305, 1984.

McEntire, R. W., E. P. Keath, D. E. Fort, A. T. Y. Lui, and S. M. Krimigis, The medium-energy particle analyzer (MEPA) on the AMPTE CCE spacecraft, IEEE Trans. Geosci. Remote Sens., GE$23,246,1985$.

Potemra, T. A., L. J. Zanetui, and M. H. Acuña, The AMPTE CCE magnetic field experiments, IEEE Trans. Geosci. Remote Sens. $G E-23,246,1985$.

Poulter, E. M., W. Allan, E. Nielsen, and K.-H. Glassmeier, Stare radar observations of a $\mathrm{Pg}$ pulsation, $J$. Geophys. Res., 88, 5668 , 1983.

Poulter, E. M., W. Allan, J. G. Keys, and E. Nielsen, Plasmatrough ion mass densities determined from ULF pulsation eigenperiods, Planet. Space Sci., 32, 1069, 1984.

Rosloker, G., H.-L. Lam, and J. V. Olson, Pc 4 giant pulsations in the moming sector, J. Geophys. Res., 84, 5153, 1979.

Saito, T., Geomagnetic pulsations, Space Sci. Rev., 10, 319, 1969.

Sato, N., H. Fukunishi, and T. Saemundsson, Operation plan for the Iceland-Syowa conjugate campaign in 1983-1985, Mem. Natl. Inst. Polar Res., Spec. Issue Jpn., 31, 169, 1984.

Shelley, E. G., A. Ghielmetti, E. Hertzberg, S. J. Battel, K. Altwegg- 
von-Burg, and H. Balsiger, The AMPTE/CCE hot-plasma composition experiment (HPCE), IEEE Trans. Geosci. Remote Sens., GE$23,241,1985$.

Singer, H. J., W. J. Hughes, and C. T. Russell, Standing hydromagnetic waves observed by ISEE 1 and 2: Radial extent and harmonic, J. Geophys. Res., 87, 3519, 1982.

Southwood, D. J., The behavior of ULF waves and particles in the magnetosphere, Planet. Space Sci., 21, 53, 1973.

Southwood, D. J., Some features of field line resonances in the magnetosphere, Planet. Space Sci., 22, 483, 1974.

Southwood, D. J., A general approach to low-frequency instability in the ring current plasma, J. Geophys. Res., 81, 3340, 1976

Sugiura, M., and C. R. Wilson, Oscillation of the geomagnetic field lines and associated magnetic penurbations at conjugate points, $J$. Geophys. Res., 69, $1211,1964$.

Takahashi, K., and R. L. McPherron, Standing hydromagnetic waves in the magnetosphere, Planet. Space Sci., 32, 1343, 1984.

Takahashi, K., B. J. Anderson, and R. J. Strangeway, AMPTE CCE observations of Pc 3-4 pulsations at $L=2-6, J$. Geophys. Res., 95, 17,179, 1990a.

Takahashi, K., R. W. McEntire, A. T. Y. Lui, and T. A. Potemra, Ion flux oscillations associated with a radially polarized transverse Pc 5 magnetic pulsation, J. Geophys. Res., 95, 3717, 19906.

Tonegawa, Y., and N. Sato, Conjugate area study of giant geomagnetic pulsations, paper presented at Chapman Conference on Plasma Waves and Instabilities in Magnetospheres and at Comets, AGU, Sendai/Mt. Zao, Japan, Oct. 12-16, 1987.
Tsyganenko, N. A., Global quantitative models of the geomagnetic field in the cislunar magnetosphere for different disturbance levels, Planet. Space Sci., 35, 1347, 1987.

Walker, A. D. M., R. A. Greenwald, W. F. Stuart, and C. A. Green, STARE auroral radar observations of Pc 5 geomagnetic pulsations, J. Geophys. Res., 84, 3373, 1979.

Veldkamp, J., A giant geomagnetic pulsation, J. Atmos. Terr. Phys. $17,320,1960$.

H. Lühr and J. Warnecke, Institut für Geophysik und Meteorologie, Technische Universität Braunschweig, Mendelssohnstrasse 3, 3300 Braunschweig, Germany.

N. Sato, National Institute of Polar Research 9-10 Kaga 1-chome. Itabashi-ku, Tokyo 173, Japan.

H. E. Spence, Space and Environment Technology Center, The Aerospace Corporation, M2-260, P.O. Box 92957, Los Angeles, CA 90009.

K. Takahashi, Applied Physics Laboratory, The Johns Hopkins University, Johns Hopkins Road, Laurel, MD 20723-6099.

Y. Tonegawa, Department of Aeronautics and Astronautics, Tokai University, Hiratsuka 259-12, Japan.

(Received October 7, 1991;

revised February 6, 1992;

accepted February 6, 1992.) 